\title{
Investigation and Reflection on the Postgraduates Employment Status in the Post-Financial Crisis Background
}

\author{
Rong Feng \\ Institute of Higher Education, Beihang University, Beijing, China \\ fengrong@buaa.edu.cn
}

\begin{abstract}
Postgraduates employment is an important outcome of the higher education sectors, and it is the fundamental way to achieve self-worth for the majority of postgraduates. The employment of college students is persistently impacted by the international and domestic situations. Under the current circumstance, this research is carried on the aspects of employment cognition, employment psychological, employment orientation, employment behavior and employment guidance demand for this year's graduates, which could help us deeply understand the development needs of graduate employment, and enhance the pertinence of the graduate employment guidance.
\end{abstract}

Index Terms - graduate, employment cognition, employment guidance

\section{Introduction}

As the global economy has entered a relatively stable period since 2011, with the adjustment of the international cooperation and the cooperation in the institutional field, some scholars say that the world economy has entered a postfinancial crisis era, in current economy situations. In such a new environment of economy, the labor market is still influenced by the changing of the economic growth point structure in China. The total employment pressure and the structural contradictions coexist in China and the postgraduate employment remains grim ${ }^{[1]}$, which are pointed out by Yuan Guiren, the minister of education, on the 2011 national college graduates employment conference. In the current employment environment, by the way of empirical research, the small sample survey on the postgraduates employment of a Beijing university graduating students is carried out, where the graduate employment status is learned from the five aspects of employment cognition, employment psychological, employment orientation, employment behavior and employment guidance demand, and have an insight into the characteristics and needs of postgraduates employment, in order to carry out targeted graduate employment guidance, and enhance the quality of higher education personnel employment.

\section{Methodology}

\section{A. Survey Implementation}

The survey questionnaire is implemented by using the stratified cluster sampling method, with the surveys samples coming from the fresh graduating students in 2013 of a Beihang university. The questionnaire is mainly composed by closed multiple choices, where the five aspects is covered, that is, employment cognitive, employment psychological, employment orientation, employment behavior, employment guidance requirement. Based on the survey questionnaire, 50 postgraduates from the sample were chosen for an in-depth interview, in order to learn the micro factors impact on the individual graduate employment.

\section{B. Sample}

2800 questionnaires are distributed to the fresh graduating students in 2013 of a Beijing university, and the valid recovery is 2260 , where the effective rate is $80.7 \%$. The selected sample is composed by 1408 male $(62.3 \%)$ and 852 female $(37.7 \%)$. The proportion of the professional graduate sample in science and engineering, humanities and management match with the proportion of the total.

\section{Data Analysis}

Coding for the valid questionnaires, the SPSS for windows V.19.0 statistical software is used to statistical data processing, where the analysis of frequency and chi-square test methods are adopted.

\section{Research Analysis}

A. Most graduate students said job-hunting is affected by the economic situation

1) Survey found that most graduate students said jobhunting is affected by the economic situation, different gender, professional difference is obvious. For 'what do you think your job-hunting is affected by the financial crisis?', 34.5\% of graduate students think 'influence', $51.8 \%$ of graduate students think 'has a little influence', said 'no impact' graduate student only $13.7 \%$ of survey.

TABLE I. Evaluation of different professional graduate students

\begin{tabular}{|c|c|c|c|c|}
\hline Options & $\begin{array}{c}\text { Science and } \\
\text { engineering }\end{array}$ & $\begin{array}{c}\text { Humanities and } \\
\text { social science }\end{array}$ & $\begin{array}{c}\text { Managemen } \\
\text { t science }\end{array}$ & All \\
\hline $\begin{array}{c}\text { Great } \\
\text { influence }\end{array}$ & $32.65 \%$ & $36.36 \%$ & $41.67 \%$ & $34.51 \%$ \\
\hline $\begin{array}{c}\text { A little } \\
\text { influence }\end{array}$ & $55.10 \%$ & $50.91 \%$ & $33.33 \%$ & $51.77 \%$ \\
\hline No effect & $12.24 \%$ & $12.73 \%$ & $25.00 \%$ & $13.72 \%$ \\
\hline
\end{tabular}

** $\mathrm{P}<0.01$ 
2) $38.6 \%$ of female graduate students think the economic situation has a great influence on the job-hunting, with the option of male graduate student ratio is only $31.88 \%$. Think the economic situation 'no impact' male graduate student for employment with $17.39 \%$, only $7.95 \%$ female graduate students.

3) As shown in TABLE I, for 'job search is affected by the economic situation', different professional graduate student assessment is different. Among them, $41.67 \%$ of management graduates think the economic situation has a great influence on the job search, engineering graduate with the option of only $32.5 \%$.

B. The overall mentality when the postgraduates look for job is positive, but part of them needs some guidance.

1) The overall mentality of the postgraduates in the process employment. For the issue of 'Which mentality you always take when you are looking for a job?' $46.8 \%$ of the postgraduates select 'Positive, believe that can be successfully employed', $30.1 \%$ of them select 'Helplessness, high stress, $20.3 \%$ of them select 'Anxiety, sometimes impatient' to be a postgraduate, which can be seen in the Figure 1 .

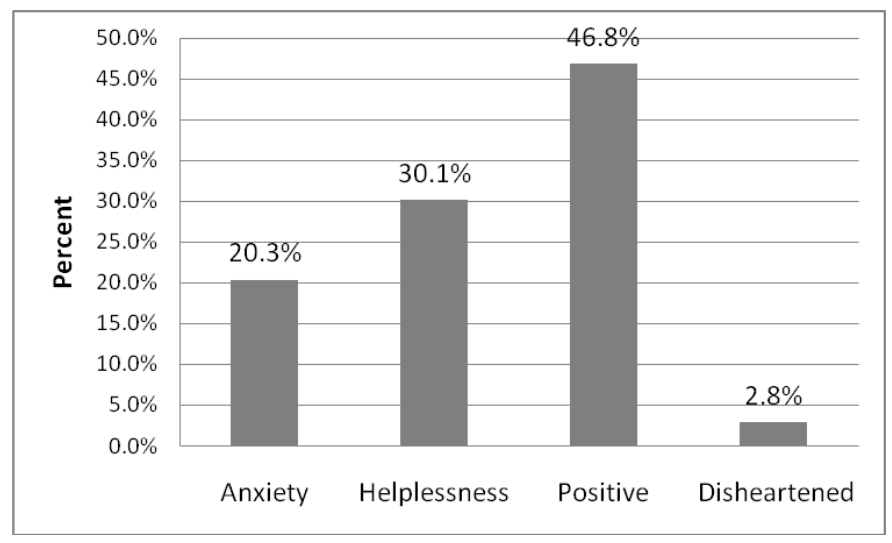

Fig. 1 The overall mentality of the postgraduates in the process employment.

2) The overall mentality of the postgraduates in the face of employment opportunities. In the face of employment opportunities, confident and optimistic state can help postgraduates to show their actual strength better, and the success possibility of employment can be improved. In the survey, nearly half of the postgraduates signify to be 'Confident' in the face of new employment opportunities, $27.5 \%$ of them hold the attitude to 'Have a try', and nearly thirty percent of them lack of confidence and show the mental state of 'Tense', 'Worried' and 'Hesitate'. Moreover, it is found that the first job hunting experience has an important impact on the employment confidence for graduates, and $61.3 \%$ of the students say that the failure experience of the initial job hunting affects the confidence in the subsequent process. Further, in-depth interviews, it is found that the lack of clarity about careers and job-hunting skills are the main reason for low success rate of the job-hunting to most postgraduates.
3) The mentality of the postgraduates in the face of being rejected in job-hunting. The postgraduates in the job-hunting process often encounter being rejected. It is found that the majority can face the reject in calmly, and take it as 'The process of accumulating experience', $10.7 \%$ of them admit that being rejected let them generate retreat emotional, and $7.3 \%$ of them feel 'anxiety, stress redoubled', as showing in Figure 2. Most postgraduates say that they need psychological guidance urgently to adjust emotion and get out of obsession brought by the rejected as soon as possible.

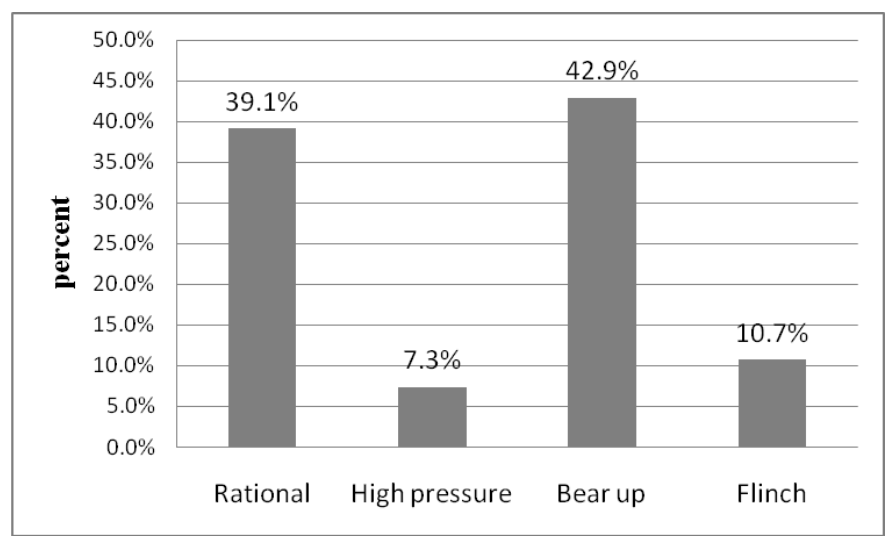

Fig. 2 The mentality of the postgraduates in the face of being rejected in jobhunting.

C. Graduate employment orientation is clearly related to individual character, choices are not balanced geographically.

1) The value orientation of graduate students to apply for a job. For the issue of "which is the value orientation on employment?' $63.3 \%$ of the postgraduates select 'To realize myself in the work', $25.2 \%$ of them select 'To solve the survival problem', besides, $7.1 \%$ and $4.4 \%$ of them select 'To serve the society', 'To make contributions to our country', respectively, which can be seen in Figure 3. This corresponds to the 'self-importance' and 'emphasizes on autonomy' features of the '80s' postgraduates.

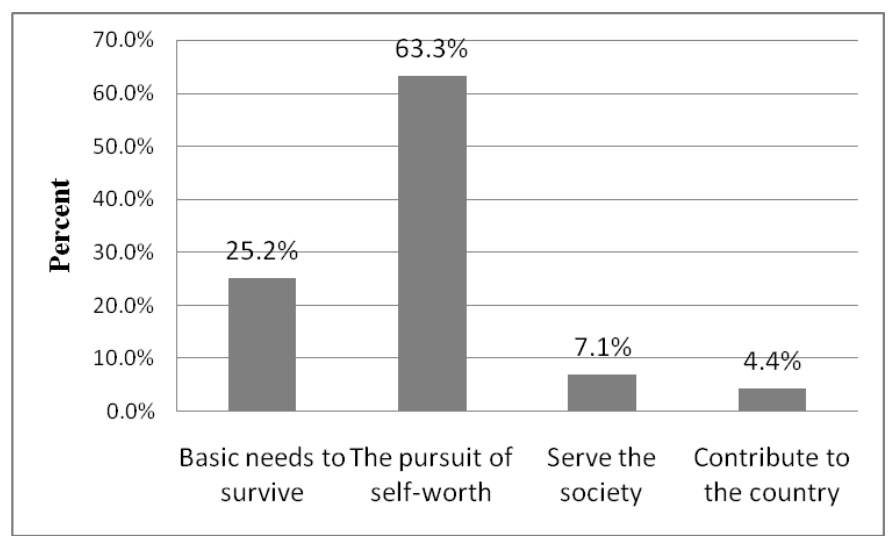

Fig. 3 The value orientation of the postgraduates on employment. 
2) For the issue of 'Which is the most attractive element on your career?' 'The development prospect of the career' is ranked as the top element $(49.1 \%)$, the next is 'Working environment' (17.3\%), and 'wages and benefits' comes to the third place (15.9\%), as shown in Figure 4. It can be seen that the postgraduates are increasingly rational on employment under the current employment environment, since they pay more attention to self-development space and growth opportunities in the career, while 'wages and benefits' are not the most valued objectives.

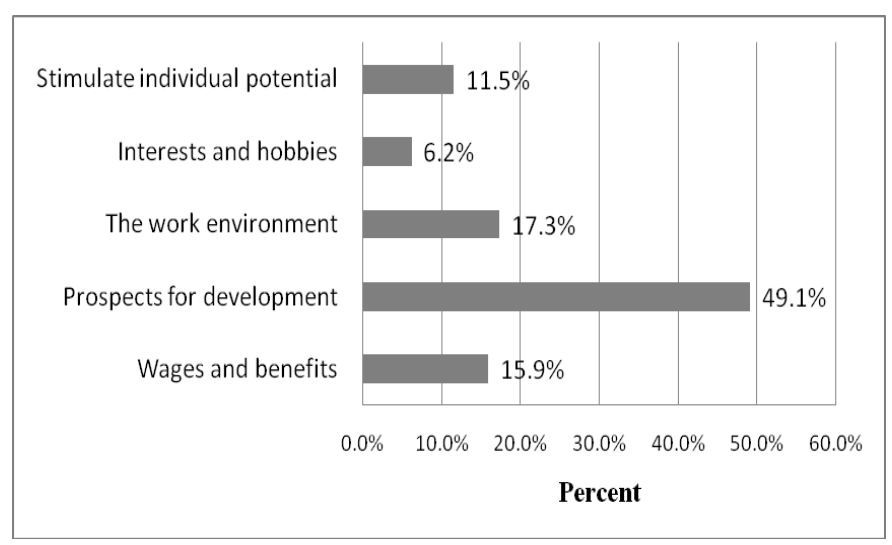

Fig. 4 The essence of graduate job value most

3) Postgraduates' choice on the employment area. Choosing a place to work at survey showed that $79.6 \%$ of the surveyed postgraduates are willing to work in Beijing, and $10.6 \%$ of them choose to work in municipality or provincial capital, while only $3.2 \%$ of them prefer to work in the western parts of the country or suburbs, as shown in Figure5. It can be seen that it is very obvious that the choosing a place to work at is imbalance for the employment. Many postgraduates would stay in Beijing, Shanghai or any other cities even though without the registered permanent residence rather than choose a better employment in other city. This is related to the imbalanced development of regional economic, on the other side, 'comparisons psychology' directly leads to part of the postgraduates taking blindness selection in the regions.

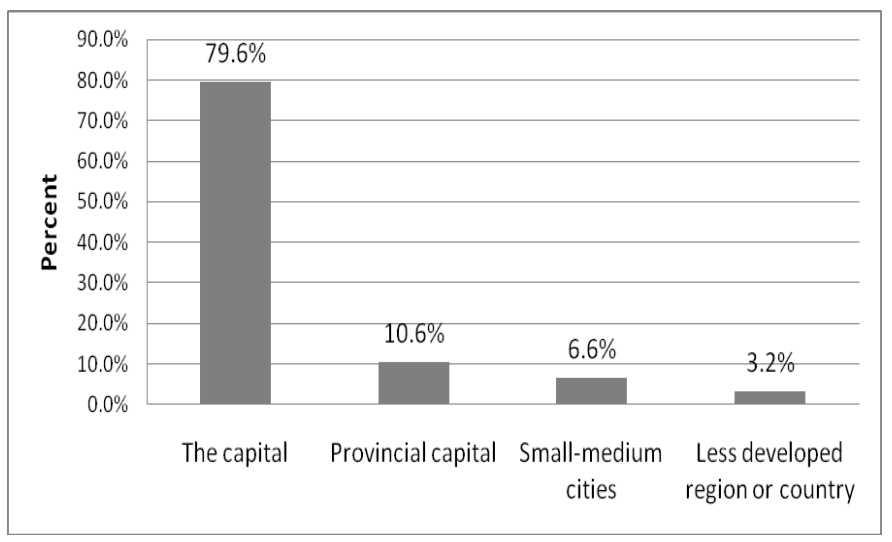

Fig. 5 The choice of regions of the postgraduates on employment.

\section{$D$. The postgraduates are active and initiative in job-hunting.}

1) Frequency of the postgraduates in job-hunting. The investigation into the frequency of the postgraduates in jobhunting mainly depends on the times they apply for jobs and submit resumes. Most postgraduates show great initiatives to seek jobs. Of the total surveyed students, $20.4 \%$ apply for jobs for 3 times, $12.4 \%$ of them with 4 times, and $56.2 \%$ of them with more than 5 times. $71.8 \%$ of the postgraduate's submitted more than 20 resumes, and $48.8 \%$ of them more than 30 resume. In the in-depth interviews, some postgraduates said that they have no choices other than face the difficulties positively, even though they repeatedly didn't succeed in finding jobs. Therefore, it can be seen that the majority of postgraduates have realized that only to be more active and efficient in job-hunting; they can seize more opportunities in the recent employment environment.

2) Main channels for postgraduates on job hunting. For the issue of "Which is the main channel for your job hunting?" the top three are 'Recruitment websites' (50.4\%), 'Campus recruitment' (33.6\%) and 'Social recruitment' (8.4\%), respectively, as shown form the Figure 6. Student L said, 'The senior students told me that they applied for jobs mainly in the Campus recruitment. However, I feel that the amount of information from the Campus recruitments is limited, so we turned to Social recruitments and related websites for help, in tend to obtain the valid information at the first time'. It can be seen that more and more postgraduates have started to develop new ways to obtain employment information more actively, rather than waiting for the chance coming.

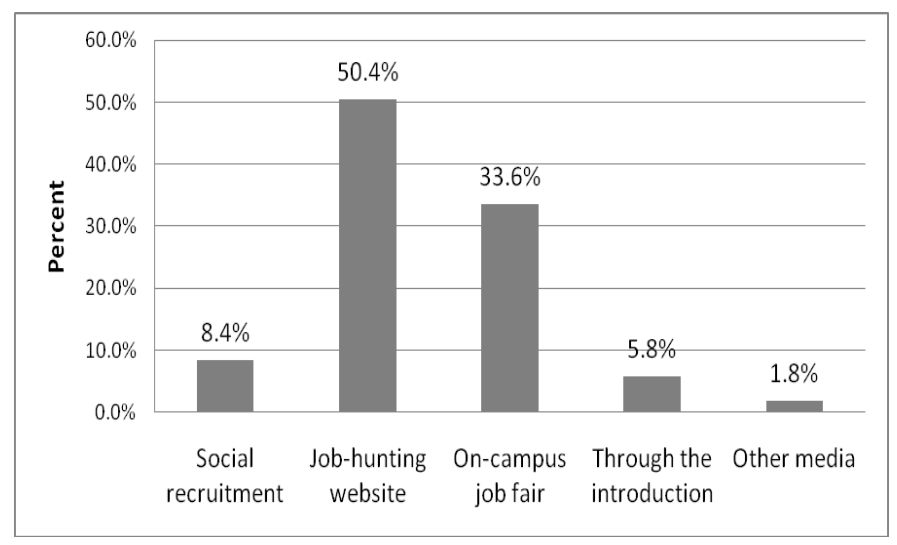

Fig.6 Statistics of the main channels for postgraduates on job hunting.

\section{Some Suggestions}

Through the survey, it can be seen that the postgraduates have objective cognitive of employment under the current employment environment. They can take optimistic and positive attitudes to face various pressures and difficulties on employment. Employment orientation is rational, and significant personalization features are showed; Employment behavior is proactive; Demands for career guidance are clear. In the meantime, we also found a small number of postgraduates exhibit depression, anxiety and other negative 
emotions in the course of employment, employment behavior of them are passive, dependent and even some choose to escape. Some postgraduates lack the necessary understanding of the employment policies, and perform the indifferent attitude of career guidance. In the aspect of school's career guidance, some issues took place, for instance, the attention to the graduate's employment psychology may not be enough, guidelines for employment are not carried out adequately, and the way of graduate's employment guidance should be improved. It makes us to gain a profound understanding of the importance and urgency to perfect the current graduate's employment guidance.

\section{A. Philosophy guidance is the focus of graduate employment.}

From the external environment, the impact of China's employment market caused by international financial environment will persist in a certain period of time. The expansion of higher education brings substantial increase in the scale of postgraduates, which dramatically enhances the employment competition. But for our 1.3 billion populations, the proportion of postgraduates is still low, still cannot totally meet the manpower needs of modern society ${ }^{[2]}$. Under the macro background of the rapid development in China, graduate employment still has a broad space for development. From the results of the survey, "the difficulty in employment" is a relative concept in current postgraduates groups, which caused by the postgraduate "excessive employment expectation" unmet state to a greater extent. Hence, we must first help students to establish a correct concept of employment in our post-graduate employment guidance, guide them to the have rational knowledge about employment environment, and overcome the "herd", "competition" and other adverse psychological. They will choose more suitable career development environment and positions from the characteristics according to their own situation and ability.

\section{B. Strengthen the mental health training of graduates looking for job.}

Through the survey, we have discovered that some students have lack of basic psychological adjustment ability when they face the stress and frustration in the job search process, job is not lost in the professional and capabilities, but is a lost in a mentality aspect. Some students with strong psychological characteristics, stabile career confidence, will show the tenacious character when facing difficulties, more likely stand out in the fierce job competition. In the process of current college graduate employment guidance, the majority of graduate professional guiding focuses on the enhancement of graduates' profession quality and employment skills, which is lack of intention on inner emotional and psychological qualities. Therefore, it is necessary to blend mental health training content into employment guidance to help students master the basic methods of psychological adjustment, as well as the necessary communication platform and help channel should be provided to postgraduates, to ensure those who get serious psychological problems could get timely psychological assistance during the process of employment.

\section{Efforts to achieve employment guidance of graduate.}

Career development is a dynamic process; the employment guidance of graduate should run throughout the stages of postgraduate training. From the survey results, the majority of postgraduates are exposed to career guidance is the eve of graduation employment mobilization and contract guidance, such as a job placement in greater degree, not really play the role to guide students to establish career planning awareness, rather improve their own quality, enhance the competitiveness of job. Therefore, universities should strive to construct an employment guidance mode in order to play a part in graduate career development-oriented, put career development concepts into all practice of postgraduate training, helping students enhance planning awareness, recognize the graduate level for their future career development important value, and guide students to improve the overall quality of the research level, practical ability, etc., as achievements conscious pursuit of their career aspirations.

\section{References}

[1] To implement the plan to do all focused employment of college graduates in 2011. http://www.ncss.org.cn/tbch/2011/.

[2] Panbo Qin, Science of Social Psychology,2007(3-4) 